years of the North Karelia study the mortality from cardiovascular disease in women aged 30 to 64 fell from 2.5 to $1 \cdot 7$ per 1000 person years compared with a fall from $7 \cdot 7$ to $6 \cdot 3$ in men. ${ }^{19}$ Mortality from stroke fell in women by half, and this is likely to be sustained by the continuing fall in blood pressure. ${ }^{8}$ A 12 year follow up study in Gothenburg of 1462 women found that $13 \%$ of women at baseline had untreated hypertension. ${ }^{20} 21$ The mean blood pressure level fell in these women during the first six years of follow up but had risen to baseline level by the twelfth year, despite $58 \%$ having treatment with specific drugs. These women, however, did not have an increased incidence either of stroke or of myocardial infarction compared with the normotensive women. Conversely, the women already having treatment at baseline, who were probably more severely hypertensive, did have a higher risk of cardiovascular events.

In summary, women with hypertension have the same risk of stroke as men but a lower risk of myocardial infarction. Given this observation, it is not surprising that no significant benefit of treatment of hypertension has been found in mildly hypertensive women. A rational policy, therefore, is to treat women with severe hypertension (diastolic blood pressure over $105 \mathrm{~mm} \mathrm{Hg}$ ) as vigorously as men but (pending any new findings from the Medical Research Council trial) not to give active treatment in mild to moderate hypertension. ${ }^{22}$ The presence of other risk factors-for example, cigarette smoking-should lead the doctor to consider intervention. Finally, as case finding is becoming an established part of general practice, at least for younger women, population based active screening programmes are unlikely to be cost effective. ${ }^{23}$

Alan J Silman

Senior Lecturer in Clinical Epidemiology,

London Hospital Medical College,

London E1 2AD

1 Hodes C, Rogers PA, Everitt MG. High blood pressure: detection and treatment by general practitioners. BrMed J 1975;ii:674-7.

2 Veterans Administration Co-operative Study Group on Antihypertensive Agents. Effects of (1) averaging 115 through $129 \mathrm{~mm} \mathrm{Hg}$. JAMA 1967;202:116-22.

3 Veterans Administration Co-operative Study Group on Antihypertensive Agents. Effects of treatment on morbidity in hypertension: results in patients with diastolic blood pressure averaging 90 through $114 \mathrm{~mm} \mathrm{Hg}$. $f A M A$ 1970;212:1143-52.

4 Multiple Risk Factor Intervention Trial Research Group. Multiple risk factor intervention trial. Risk factor changes and mortality results. JAMA 1982;248:1465-77.

5 Rose G, Tunstall-Pedoe HD, Heller RF. UK heart disease prevention project: incidence and mortality results. Lancet 1983;i:1062-6. 1974; iii:60-3.

7 Kannel WB, Wolf PA, Verter J, McNamara P. Epidemiologic assessment of the role of blood pressure in stroke. The Framingham study. JAMA 1970;214:301-10.

8 Puska P, Salonen JT, Nissinen A, et al. Changes in risk factors for coronary heart disease during 10 years of a community intervention programme (North Karelia project). Br Med $1983 ; 287: 1840-4$.

9 Miall WE, Chinn S. Screening for hypertension: some epidemiological observations. Br Med $\mathcal{J}$

1973:iii: $595-600$.
10 Society of Actuaries and Association of Life Insurance Medical Directors of America. Blood pressure study 1979. Chicago: Recording and Statistical Corporation, USA, 1980.

Kannel WB. Role of blood pressure in cardiovascular morbidity and mortality. Prog Cardiovasc Dis 1974;17:5-24.

12 Hypertension Detection and Follow-up Program Co-operative Group. Five year findings of the hypertension detection and follow-up program. I. Reduction in mortality of persons with high blood pressure, including mild hypertension. FAMA 1979;242:2562-71. hypertension detection and follow-up program. II. Mortality by race, sex and age. $J A M A$ 1979;242:2572-7.

14 Report by the Management Committee. The Australian therapeutic trial in mild hypertension. Lancet 1980;i:1261-7.

15 Barlow DH, Beevers DG, Hawthorne VM, Watt HD, Young AR. Blood pressure management at

screening and in general practice. Br Hear $\mathcal{F} 1977 ; 39: 7-12$.
$6 \mathrm{Heller} R \mathrm{RF}$, Rose G. Current management of hypertension in general practice. $\mathrm{Br}$ Med $\mathcal{J}$ 1977; ;:1442-4.

17 Hypertension Detection and Follow-up Program Co-operative

18 Tuomilehto J, Nissinen A, Salonen JT, Kottke TE, Puska P. Community programme for contro

18 Tuomilehto J, Nissinen A, Salonen JT, Kottke TE, Puska P. Community programme for control
of hypertension in North Karelia, Finland. Lancet $1980 ;$;i: $900-4$.
19 Salonen JT, Puska P, Mustaniemi H. Changes in morbidity and mortality during comprehensive community programme to control cardiovascular diseases during 1972.7 in North Karelia. $B$ Med F 1979; ii:11178-83.

20 Sigurdsson JA, Bengtsson C. Prevalence and management of arterial hypertension in a population sample of Swedish women. Scand F Soc Med 1981;9:41-7.

21 Sigurdsson JA, Bengtsson C, Lapidus L, Lindquist O, Rafnsson V. Morbidity and mortality in relation to blood pressure and antihypertensive treatment. A 12-year follow-up study of a population sample of Swedish women. Acta Med Scand (in press).
Medical Research

Medical Research Council Working Party on Mild to Moderate Hypertension. Randomised controlled trial

23 Bryers F, Hawthorne VM. Screening for mild hypertension: costs and benefits. $\mathcal{J}$ Epidemiol Community Health 1978;32:171-4.

\section{Children in a persistent vegetative state}

Karen Quinlan has been unconscious since she lapsed into coma on 15 April 1975. At first her life was maintained by mechanical ventilation, but in May 1976 a New Jersey court authorised her removal from the respirator. Contrary to expectations Karen did not die; eight years later she still lies in a New Jersey nursing home, unable to communicate or consciously to respond to her family, doctors, nurses, or environment. She is fed artificially and nursed night and day. She has attracted the attention from all parts of the world of doctors, philosophers, theologians, and lawyers who view her plight as a critical landmark in discussions on the uses and abuses of modern medical technology and the doctrine of ordinary and extraordinary means of prolonging life. Other patients have survived for much longer, but she is the best known example of the persistent vegetative state described recently as "a fate worse than death."

The term "persistent vegetative state" was suggested in 1972 to describe those patients with irreversible brain damage, usually from trauma or hypoxic ischaemia of the brain, and who on recovery from deep coma pass into a state of seeming wakefulness and reflex responsiveness but do not return to a cognitive sapient state. ${ }^{2}$ It is the result of destruction of the cerebral cortex or its integrating connections with sufficient preservation of the brain stem to sustain the vegetative functions-respiration, circulation, and so on. The persistent vegetative state must be distinguished from the better defined brain death (more correctly, brain stem death), where the patient does not survive once respiratory support is withdrawn. ${ }^{34}$ It must also be distinguished from other rare syndromes of prolonged unresponsiveness caused by selective damage to parts of the brain stem. ${ }^{56}$ Patients in the persistent vegetative state may survive almost indefinitely so long as they receive adequate nutrition, a high standard of nursing care, and are protected against infection.

The persistent vegetative state is being seen more often in children as improved techniques of resuscitation and intensive care have increased the chances of survival after severe trauma to the head or cardiorespiratory arrest. About $12 \%$ of adults who survive non-traumatic coma remain in a vegetative state. ${ }^{78}$ In children the incidence is probably less, but accurate estimates are difficult to make because of the heterogeneity of most studies and their small numbers. The type and duration of coma also influence the prognosis, which is poor after cardiorespiratory arrest, ${ }^{9}$ better after metabolic or encephalitic coma, ${ }^{10}$ and best of all after severe head injury. ${ }^{11}$ Children in coma are more unpredictable than adults, perhaps because their brains are at different stages of development and more resistant to various insults. This uncertainty should make us particularly cautious in making hasty judgments about prognosis. ${ }^{12}$

For their families children who remain in a persistent vegetative state are tragedies of great poignancy. For doctors and nurses they pose difficult moral and ethical dilemmas about the appropriate use of measures to prolong life when there is virtually no hope of a life of meaning and quality. For the health services they are a considerable burden on resources that might be used more appropriately for other patients. Criteria have been established for the determination of brain stem death and the withdrawal of respiratory support. ${ }^{13}$ We need to establish criteria for the persistent vegetative state and the appropriate action that should follow. 
Is it possible to identify the persistent vegetative state with reasonable certainty? A review of the relevant publications suggests that it is, provided that an expert serial neurological assessment is made beginning within hours of the onset of coma and combined with investigations such as the electroencephalogram, evoked potentials, and the modern imaging techniques of computed tomography and nuclear magnetic resonance scanning. The outlook cannot be predicted with sufficient accuracy from clinical examination alone.

Several studies have shown that early ( $<24$ hours) development of decorticate and decerebrate responses, roving conjugate eye movements, and spontaneous blinking have some predictive value for the persistent vegetative state. ${ }^{14}$ is One study of hypoxic-ischaemic brain damage found that all the patients regained brain stem function within days of onset of coma; opened their eyes within two weeks; most had roving conjugate eye movements, yet none had evidence of cognitive awareness. ${ }^{16}$ Stepwise discriminant analysis of clinical variables has shown that while the prognosis is more accurate if the examination is performed between two and 12 hours after the onset of coma, $8 \%$ of children may be classified erroneously. ${ }^{17}$ In a smaller study children with initially unrecordable visual evoked potentials to diffuse flash had a uniformly poor outcome. ${ }^{18}$

Unfortunately the early signs of "awakening" in a child who has been deeply comatose may create a false sense of optimism about eventual recovery in the parents (and in doctors and nurses unfamiliar with persistent vegetative state). Adequate time is essential not only for complete neurological assessment and other tests but to allow the family to adjust to the tragedy and feel certain that everything possible has been done. Every opportunity should be taken to enrich the child's environment for maximum stimulation and to identify signs of awareness. Tapes of favourite voices and music should be available. Family members should be encouraged to participate in ways that may also allow them to face the future realistically and help them in working out their grief. Claims have been made for "coma arousal kits" and systematic intensive programmes of stimulation using all five sensory pathways, but they are difficult to evaluate without properly matched trials. ${ }^{19}$

Recovery is exceptionally rare in patients who have been in a vegetative state for one month. ${ }^{2021}$ Nevertheless, for children especially, a minimum period of three months seems prudent before they are deemed to be permanently unconscious and "for all practical purposes dead." The subsequent management of permanently unconscious patients rouses strong feelings, amply illustrated in the commentaries on controversial cases. ${ }^{22}$ No matter how carefully the medical criteria are selected, and no matter how accurate they are in predicting outcome, there will always be some uncertainty. The medical prognosis should not be the only determinant of the continuation or discontinuation of treatment. There must be some room for discretion based on values affecting individual families-personal, religious, and cultural. Most people probably would agree with the principle contained in the papal allocution that when deep unconsciousness is judged to be permanent, "extraordinary means to maintain life are not obligatory." ${ }_{23}$ What does this mean in the persistent vegetative state, where, unlike brain stem death, "life" is not dependent on mechanical ventilation but on such ordinary measures as tube feeding and antibiotics? I believe that anything, including feeding, that prolongs this non-human or artificial life is wrong for the child, wrong for the family, and wrong for society. For many people, the denial of such a basic necessity as food is repugnant emotionally and psychologically. Although Karen Quinlan's parents petitioned to have her removed from a respirator knowing that she might die, they continue to believe that the withdrawal of food and antibiotics would be morally wrong. ${ }^{24}$

As I have argued in another context, these intensely difficult and individual decisions must be made by the doctors primarily responsible for the care of the child, but with the full understanding and agreement of the parents. ${ }^{25}$ It is unusual for a family and physicians to disagree if there is honesty, sensitivity, and trust among the parties concerned; if there has been care in establishing the diagnosis; and if there has been time for reflection on the implications of continuing or discontinuing treatment. The doctor must protect the child from further irresponsible use of dehumanising technology and provide support for the grieving family in joint efforts to ensure comfort and dignity in death.

A G M CAMPBELL

Professor of Child Health

University of Aberdeen,

Aberdeen AB9 2ZD

Feinberg WM, Ferry PC. A fate worse than death: the persistent vegetative state in childhood. Am F Dis Child 1984;138:128-30.

Jennett B, Plum F. Persistent vegetative state after brain damage: a syndrome in search of a name. Lancet 1972; ; $734-7$.

Pallis C. ABC of brain stem death. Br Med f 1982;285:1409-12.

4 Cranford RE, Smith HL. Some critical distinctions between brain death and the persisten vegetative state. Ethics in Science and Medicine 1979;6: 199-209.

Skultety FM. Clinical and experimental aspects of akinetic mutism. Arch Neurol 1968;19:1-14 Golden GS, Leeds N, Kremenitzer MW. The "locked-in" syndrome in children. $\mathcal{J}$ Pediatr 1976;89:596-8

ates D, Caronna JJ, Cartlidge NE. A prospective study of non-traumatic coma: methods and

8 Levy DE, Knill-Jones RP, Plum F. The vegetative state and its prognosis following non-traumatic

coma. Ann NY Acad Sci 1978;315:293-306.
Seshia SS, Chow PN, Sankaran K. Coma following cardiorespiratory arrest in childhood. Dev Med Child Neurol 1979;21:143-53.

10 Margolis LH, Shaywitz BA. The outcome of prolonged coma in childhood. Pediatrics 1980;65:477-83.

11 Bruce DA, Schut L, Bruno LA, Wood JH, Sutton LN. Outcome following severe head injuries in children. $\mathcal{F}$ Neurosurg 1978;48:679-88.

12 Johnston RB, Mellits ED. Paediatric coma: prognosis and outcome. Dev Med Child Neurol

$1980 ; 22: 3-12$.
Royal Colleges and their faculties in the United Kingdom. Statement issued by the honorary secretary of the conference of medical royal colleges and their faculties in the United Kingdom

14 Gillies JD, Seshia SS. Vegetative state following coma in childhood: evolution and outcome. Dev

15 Levy DE, Bates D, Caronna JJ, et al. Prognosis in non-traumatic coma. Ann Intern Med 1981;94:293-301.

16 Dougherty JH, Rawlinson DG, Levy DE, Plum F. Hypoxic-ischemic brain injury and the vegetative state: clinical and neuropathologic correlation. Neurology 1981;31:991-7.

17 Seshia SS, Johnston B, Kasian G. Non traumatic coma in childhood: clinical variables in prediction of outcome. Dev Med Child Neurol 1983;25:493-501.

18 Reet PS-V, Glaze DG, Hrachovy RA. A preliminary prospective neurological study of coma in children. Am J Dis Child 1984;138:492-5.

LeWinn EB, Dimanescu MD. Environmental deprivation and enrichment in coma. Lancet

20 Higashi K, Hatano M, Abiko S, et al. Five-year follow-up study of patients with persistent vegetative state. F Neurol Neurosurg Psychiatry $1981 ; 44: 552-4$.

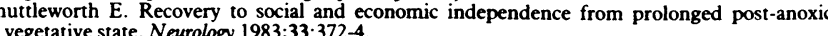
22 Field RE, Romanus RJ. A decerebrate patient: eighteen years of care. Conn Med 1981;45:717-24 23 McCormick RA. To save or let die: the dilemma of modern medicine. JAMA 1974;229:172-6. 24 Quinlan J, Quinlan J. Karen Ann: the Quinlans tell their story. New York: Doubleday, 1977 25 Campbell AGM. The right to be allowed to die. F Med Ethics 1983;9:136-40. 